\title{
A "ajuda" do programa bolsa família: representações da transferência de renda para seus beneficiários
}

\section{The "help" of the familiy grant program: representations of income transfers to their beneficiaries}

Viviane Marinho da Costa Luciana Maria Cerqueira Castro² Shirley Donizete Prado ${ }^{3}$

Silvia Ângela Gugelmin ${ }^{3}$

\footnotetext{
1 Programa de Pós-Graduação em Alimentação, Nutrição e Saúde. Instituto de Nutrição, Universidade do Estado do Rio de Janeiro. Rio de Janeiro, RJ, Brasil.

${ }^{2}$ Departamento de Nutrição Social. Instituto de Nutrição. Universidade do Estado do Rio de Janeiro. Rio de Janeiro, RJ, Brasil.

${ }^{3}$ Programa de Pós-Graduação em Alimentação, Nutrição e Saúde. Departamento de Nutrição Social. Instituto de Nutrição. Universidade do Estado do Rio de Janeiro. Rio de Janeiro, RJ, Brasil.

Correspondência / Correspondence Viviane Marinho da Costa E-mail: viviane_mcosta@yahoo.com.br
}

\section{Resumo}

O Programa Bolsa Família (PBF) faz parte da política social brasileira de combate à fome de maior magnitude e abrangência. Destinado às famílias em situação de pobreza e extrema pobreza, associa a transferência do benefício financeiro ao acesso a direitos sociais básicos por meio de condicionalidade. Três eixos centrais e indissociáveis deveriam compor as ações deste programa: a transferência de renda; o acesso aos serviços públicos de saúde e educação; e o acesso a trabalho e renda por meio de programas complementares. No entanto, é notório que a transferência de renda tem centralidade no PBF. Este trabalho visou identificar as representações de beneficiários do PBF sobre o benefício financeiro recebido e, com isso, discutir a relação estabelecida entre esses indivíduos e o PBF. Foram realizadas 23 entrevistas semiestruturadas, analisadas pela abordagem da hermenêutica-dialética. As entrevistas trouxeram como síntese das representações dos beneficiários a categoria ajuda. Os principais pontos que destacamos sobre esta categorização são: a constatação de uma insuficiência do benefício diante das necessidades da família; a desconsideração deste benefício enquanto direito, ou seja, o entendimento de que o mesmo é algum tipo de concessão; e o sentimento de desfiliação do mercado de trabalho, que gera desvalorização pessoal e sensação de inércia social.

Palavras-chave: Programas Patrocinados pelo Governo. Programas de Bem-Estar. Direitos Humanos. Programa Bolsa Família. Programas de Transferência de Renda. Direitos Humanos. 


\section{Abstract}

The Family Grant Program (PBF) is currently the Brazilian social policy to fight hunger of greater magnitude and scope. Aimed at families in poverty and extreme poverty, it associates transfer of financial benefits with access to basic social rights through conditionality. Three main axes and interrelated actions should make this program: income transfer, access to public health and education, and access to employment and income through complementary programs. However, it is clear that income transfer plays central role in PBF. This study aimed to identify the representations of $\mathrm{PBF}$ beneficiaries about the financial benefits received and, therefore, discuss the relation between these individuals and the program. We conducted 23 interviews, and analyzed them through the hermeneutic-dialectic approach. The interviews summarized the representations of beneficiaries with the category aid. The main points we highlight on this categorization are: a lack of benefit considering the needs of the family; disregard of this benefit as a right, ie, understanding that it is some kind of grant; and disaffiliation from the feeling of labor market, which generates feelings of worthlessness and social inertia.

Key words: Government Programs. Health Promotion. Human Rights. Family Grant Program. Cash Transfer Programs.

\section{Introdução}

o Programa Bolsa Família (PBF) faz parte da política social brasileira de transferência de renda para o combate à fome de maior magnitude e abrangência. Voltado para a erradicação da pobreza absoluta, o programa atende a milhões de famílias brasileiras selecionadas do Cadastro Único de Programas Sociais do governo (CadÚnico).

Implementado logo no primeiro ano de governo do presidente Lula e instituído pela Medida Provisória no 132, de 20 de outubro de 2003, o PBF se apresenta como a parte mais emergencial da política de erradicação da fome e da pobreza brasileiras. Ele introduz a transferência direta de renda como medida de alívio das necessidades imediatas de famílias em situação de vulnerabilidade (pobreza e extrema pobreza), associando a transferência do benefício financeiro com o acesso aos direitos sociais básicos (saúde, educação e assistência social) através de condicionalidades. 
Apesar de muito questionado quanto à capacidade de alcançar suas ambições, as pesquisas sobre o PBF vêm demonstrando seu potencial para modificação do quadro agudo de pobreza na sociedade brasileira. O 4º Relatório Nacional de Acompanhamento dos Objetivos do Milênio ${ }^{1}$ informa a diminuição dos índices de pobreza extrema de 12\% em 2003 para 4,8\% em 2008. Esses dados dão força ao PBF no cenário nacional, no movimento de erradicação da pobreza extrema.

Para participar do PBF, as famílias devem se enquadrar nos critérios de elegibilidade do programa (que se resumem centralmente à renda familiar per capita) e estar cadastradas no CadÚnico. Nesse cadastro são inseridas todas as famílias que têm renda de até meio salário mínimo per capita, já que o CadÚnico é utilizado para selecionar o público de diversas políticas sociais. Com a entrada da família no programa, é enviado o cartão magnético da Caixa Econômica Federal, órgão responsável pela transferência do benefício diretamente da União para o beneficiário.

A focalização, parte central no desenho do programa, tem sua base no conceito de discriminação positiva. Assim, o programa elege seu público-alvo de acordo com suas necessidades imediatas para sobrevivência. A renda é o critério utilizado para mensurar o tamanho da necessidade e é o principal identificador das famílias que podem se inscrever no programa.

No quadro abaixo, podemos visualizar os tipos e valores de benefício concedidos no ano de 2012.

Quadro 1. Critérios de elegibilidade e benefícios do PBF. 2012.

\begin{tabular}{|c|c|c|c|c|c|}
\hline \multicolumn{2}{|c|}{ Critério de Elegibilidade } & \multirow[b]{2}{*}{$\begin{array}{c}\text { Benefício } \\
\text { Básico }\end{array}$} & \multirow{2}{*}{$\begin{array}{c}\text { Ocorrência } \\
\text { de crianças / } \\
\text { Adolescentes 0- } 15 \\
\text { anos, Gestantes e } \\
\text { Nutrizes (máximo de } \\
3 \text { benefícios) }\end{array}$} & \multirow{2}{*}{$\begin{array}{l}\text { Ocorrência de } \\
\text { Adolescentes } \\
\text { entre } 16 \text { e } 17 \text { anos } \\
\text { (máximo de } 2 \\
\text { benefícios) }\end{array}$} & \multirow{2}{*}{$\begin{array}{c}\text { Variação do } \\
\text { beneficio } \\
\text { para a faixa } \\
\text { de renda }\end{array}$} \\
\hline $\begin{array}{c}\text { Situação } \\
\text { das } \\
\text { Famílias }\end{array}$ & $\begin{array}{c}\text { Renda } \\
\text { Mensal Per } \\
\text { capita }\end{array}$ & & & & \\
\hline Pobreza & $\begin{array}{c}\text { De } \\
\mathrm{R} \$ 70,01 \mathrm{a} \\
\mathrm{R} \$ 140,00\end{array}$ & --- & $\mathrm{R} \$ 32,00$ & $\mathrm{R} \$ 38,00$ & $\begin{array}{l}\mathrm{R} \$ 32,00 \mathrm{a} \\
\mathrm{R} \$ 172,00\end{array}$ \\
\hline $\begin{array}{c}\text { Extrema } \\
\text { Pobreza }\end{array}$ & $\begin{array}{c}\text { Até } \\
\mathrm{R} \$ 70,00\end{array}$ & $\mathrm{R} \$ 70,00$ & $\mathrm{R} \$ 32,00$ & $\mathrm{R} \$ 38,00$ & $\begin{array}{l}\mathrm{R} \$ 70,00 \mathrm{a} \\
\mathrm{R} \$ 242,00\end{array}$ \\
\hline
\end{tabular}

Fonte: BRASIL, Ministério do Desenvolvimento Social e Combate à Fome, 2012. 
O PBF prevê que a titularidade da família beneficiária será preferencialmente da mulher, promovendo empoderamento à mesma e reconhecendo sua capacidade de identificar as necessidades da família. Segundo estudo do IBASE, ${ }^{2}$ as mulheres titulares referem que após o recebimento do benefício do PBF "sentem-se mais independentes financeiramente", além de afirmarem que "aumentou seu poder de decisão em relação ao dinheiro da família".

Segundo o Ministério do Desenvolvimento Social e Combate à Fome (MDS), o PBF pauta-se na articulação de três dimensões essenciais à superação da fome e da pobreza: a) promoção do alívio imediato da pobreza, por meio da transferência direta de renda à família; b) reforço ao exercício de direitos sociais básicos nas áreas de Saúde e Educação, por meio do cumprimento das condicionalidades, o que contribui para que as famílias consigam romper com o ciclo da pobreza entre gerações; c) coordenação de programas complementares, que têm por objetivo o desenvolvimento das famílias, de modo que os beneficiários do PBF consigam superar a situação de vulnerabilidade e pobreza.

Ainda segundo o MDS, os programas complementares objetivam potencializar os efeitos das transferências condicionadas de renda na redução das desigualdades, "promovendo um salto qualitativo que conduza as famílias de uma situação de redução da pobreza, para outra de superação sustentada de qualquer forma de vulnerabilidade". ${ }^{3}$

Buscando novas perspectivas para o conhecimento acerca do PBF, objetivamos, neste estudo, nos aproximar das representações das famílias assistidas pelo programa sobre o benefício financeiro recebido e discutir a relação estabelecida entre esses indivíduos e o programa que os assiste.

\section{Percurso metodológico}

Este artigo é derivado da dissertação de mestrado da primeira autora, intitulada Programa Bolsa Família e as condicionalidades de saúde: percepções de beneficiários do município do Rio de Janeiro, estudo que objetivou identificar representações sobre este programa de transferência de renda e sobre as condicionalidades de saúde associadas a ele.

Foram utilizadas entrevistas semiestruturadas. A opção de utilizarmos este tipo de entrevista não foi aleatória e converge com a abordagem desta pesquisa, de caráter exploratório. Esse tipo de entrevista nos permite uma aproximação e conhecimento do tema, sem limitar novas descobertas. ${ }^{4}$

Privilegiamos o olhar dos beneficiários deste programa, entendendo esses indivíduos como protagonistas desta política, que podem levantar temas relevantes para a compreensão da realidade social instaurada com o PBF. São eles que vivenciam, a cada dia, as mudanças, impactos e repercussões que essa política tem de forma direta em suas vidas. Consideramos então este recorte 
como um ponto peculiar de nosso estudo, trazendo à tona a visão de determinados sujeitos que usualmente é pouco destacada.

O trabalho de campo foi realizado na Área Programática de Saúde 5.3, no município Rio de Janeiro. A escolha desse local se deu através de um olhar sobre as práticas realizadas no acompanhamento das condicionalidades do programa na cidade do Rio de Janeiro. Em visitas ao Instituto de Nutrição Annes Dias (INAD), da Secretaria Municipal de Saúde e Defesa Civil do Rio de Janeiro (SMSDC-RJ) notamos que a Área Programática 5.3 exibia, em algumas unidades, uma metodologia diferenciada para acompanhar seus beneficiários, além de maior participação na gestão municipal do programa, no grupo intergestor. "Dessa forma, decidimos investigar quais seriam de fato essas práticas, como elas se expressavam em cada unidade visitada, e que efeitos poderiam ser gerados por elas no acompanhamento e implementação do programa.

Com base no diálogo com a coordenação da AP 5.3 e nos dados do INAD, foram selecionadas três unidades de saúde (uma policlínica, uma unidade básica de saúde e uma unidade de Estratégia de Saúde da Família). Essas unidades receberam visitas entre abril e maio de 2009, quando realizamos observação participante e entrevistas semiestruturadas. Todas as entrevistas foram realizadas pela mesma pessoa e foram gravadas em aparelho digital, sendo posteriormente transcritas pela própria entrevistadora.

Foram entrevistados 23 titulares do programa, selecionados aleatoriamente nas Unidades de Saúde da região de Santa Cruz do município do Rio de Janeiro. No momento da entrevista, os participantes da pesquisa se encontravam nas unidades de saúde para acompanhar as condicionalidades de saúde do PBF. Para preservar a identidade dos entrevistados, utilizamos números e letras para identificar as falas. Esses códigos representam, respectivamente: número a identidade do entrevistado dentro da unidade de saúde onde ele se insere; letra - a unidade de saúde, sendo E código relativo à Estratégia de Saúde da Família, U a unidade básica tradicional e $\mathrm{P}$ a policlínica.

Este estudo foi aprovado pelo Comitê de Ética da Secretaria Municipal de Saúde do Rio de Janeiro, por meio do parecer no 23A/2009.

* O Programa Bolsa Família no Município do Rio de Janeiro conta com definições próprias que foram produzidas pela gestão municipal do programa para sua implementação. O decreto no . 24.702, de 8 de outubro de 2004, criou o grupo intergestor para elaboração e aperfeiçoamento de instrumentos adequados ao monitoramento e avaliação das condicionalidades do Programa Bolsa Família, sob coordenação da Secretaria Municipal de Assistência Social (SMAS). Além da SMAS, esse grupo é formado pelas Secretarias Municipais de Saúde e Defesa Civil (SMSDC), Educação (SME), Habitação (SMH), Esportes e Lazer (SMEL) e Fazenda (SMF). 


\section{Resultados e discussão}

Do total de entrevistados, 20 eram do sexo feminino e apenas três do sexo masculino. Esse dado é similar ao de outros estudos ${ }^{2,5}$ e está de acordo com o marco legal do PBF, que indica a predileção da mulher como titular do cartão do programa. Verificamos que os entrevistados viviam em domicílio com número médio de 4,5 pessoas.

Houve variação entre os entrevistados no quesito "escolaridade". Em média, apresentavam sete anos de frequência em estudos formais, o que representa o $5^{\underline{0}}$ ano do ensino fundamental. Oito entrevistados (34,7\%) relataram entre nove e 12 anos de frequência escolar e completaram ao menos o ensino fundamental; por outro lado, cinco $(21,7 \%)$ frequentaram a escola por menos de cinco anos, não completando sequer o primeiro ciclo do ensino fundamental.

Sobre a situação de trabalho nessas famílias, percebemos que a grande maioria dos entrevistados encontrava-se desempregada no momento da entrevista ou realizava algum tipo de trabalho informal, referido como "biscate", tais como pequenos serviços de obra, ajudante de pedreiro, venda de quentinhas e outros tipos de alimentos e outras atividades informais similares.

\section{A ajuda como representação do benefício}

Na tentativa de sintetizar e identificar aproximações ou distanciamentos nas falas dos entrevistados, identificamos forte tendência na construção da representação de um conceito sobre o benefício do PBF: a referência à ajuda, uma categoria que apareceu recorrentemente na fala dos entrevistados, assumindo diversos significados que apresentaremos a seguir.

Essa constatação não se restringe ao nosso estudo, sendo também descrita em outras pesquisas de maior abrangência. 2,** Em um primeiro momento, associar a categoria ajuda a uma política social poderia remeter exclusivamente ao assistencialismo. E não por acaso, diversas representações encontradas nos estudos citados remetem a uma relação de assistência entre o estado e o titular: doação, caridade, bolsa da criança, entre outros significados, foram verificados na literatura: 6 "[...] o medo de perder o benefício, a irregularidade do pagamento, a falta de clareza sobre critérios de elegibilidade e desligamento tenderam a fragilizar a elaboração do programa como direito social. O Bolsa Família, assim, tornou-se muitas vezes uma "caridade", "um alívio", "uma ajuda" ou "um pagamento para a criança estudar."

** Monnerat GL. Divulgação de resultados preliminares da pesquisa "Programa Bolsa Família: A implementação das condicionalidades da saúde sob a ótica dos gestores e famílias beneficiárias" em evento realizado na Faculdade de Serviço Social da UERJ. Comunicação Pessoal. 2009. 
As palavras de Magalhães et al. ${ }^{6}$ explicitam algumas das possíveis justificativas para a presença da visão assistencialista do PBF. Uma dessas justificativas se expressa na fala a seguir, em que a entrevistada demonstra sua insatisfação e incompreensão com relação aos procedimentos para definição dos valores do benefício para diferentes famílias:

"Olha, a única coisa que eu acho errado é esse benefício que para uns mais, que não precisa, outros que precisam vem pouco. É o meu caso [...] tem uns que vem baixo, tens uns que vem acima do normal, aí eu acho isso errado. Se é benefício para todos, tem que vir aquela quantia especificada para cada um. O certo é "tanto"? É cento e cinquenta? Então é cento e cinquenta pra todo mundo. Porque tem uns que recebem duzentos e pouco, entendeu, e eu acho isso supererrado." (1E)

O estudo do IBASE $^{2}$ encontrou realidade semelhante, já que $74 \%$ dos entrevistados disseram não saber por que as famílias recebem valores diferentes. Este é mais um marco da comunicação deficiente estabelecida com o beneficiário dessa política, o que repercute negativamente sobre a forma como os beneficiários se relacionam com ela. Hevia ${ }^{7}$ percebeu em seu estudo que "[...] las formas de comunicación e interlocución ente el programa y los beneficiários, puesto que se basan em cartas, médios de comunicación y otras instancias virtuales y esporádicas, generan relaciones "lejanas" entre beneficiários y el programa. Esto repercute em el poco conocimiento de los processos clave que tienen los beneficiários sobre el Programa.”

A avaliação sobre a promoção da cidadania a partir de uma política pública relaciona-se com o quanto ela permite que seu público-alvo entenda seu funcionamento. Nesse sentido, percebemos a deficiência do PBF em esclarecer uma questão-chave do programa, o cálculo do valor recebido por família, o que indica falhas de comunicação entre o beneficiário e os gestores do programa. Silva $^{8}$ alerta para a inexistência de metodologias de avaliação da potencialidade do PBF para gerar cidadania e considera fundamental o avanço nesse campo de avaliação do programa.

Outro ponto identificado na grande maioria das falas é que existe um consenso em torno do sentimento de mudança na família com a entrada no programa. Essa mudança está diretamente relacionada ao benefício financeiro, que impacta no poder de compra e de acesso a determinados bens que anteriormente eram distantes da realidade das famílias. Isso destaca o papel de centralidade que a transferência de renda (TR) assume nessa política social, como explicitado nas seguintes declarações:

"Ah! Mudou assim, no sentido de que todo mês eu posso contar, já no próprio lugar que eu já recebo, eu já vou lá e eu já compro o leite dela entendeu? Já compro um caderno, um lápis, entendeu? Tudo que na escola dá, mas eles pedem às vezes, entendeu? Falta, então... uma meia pra ir pro colégio, entendeu? Então pra mim mudou que me ajuda muito, me ajuda muito. Não vou falar que "ah, é só pra comer", não vou porque eu vou estar mentindo se eu falar isso. Mas ajuda em todos os sentido pra elas. Pra elas porque é pra elas, os benefícios delas, entendeu?" (4U) 
"Ah! Eu acho que mudou sim. Mudou porque já tá ajudando mais, assim comprar as coisas pras crianças né, não se eu posso falar, né, mas meu filho tava sem tênis, aí eu fui e comprei um "tenizinho" pra ele, né? Comprar assim frutas, as coisas que tá precisando mais, um caderno, essas coisinhas." (9P) "Assim, agora eu separo né, tem um dinheiro que é pra eles. Eu não preciso ficar me preocupando tanto, com caderno, lápis, e olha que minha turminha é grande entendeu (riso). Então são coisas que eu separo pra eles, utilizado só pra eles."(4E)

As falas apresentadas estão cheias de significados e apropriações de diversas naturezas. Nas primeiras falas, percebemos que a ajuda representa a capacidade de ter acesso a suas necessidades. Outros autores também relatam que a segurança gerada pela previsão da renda a ser recebida no próximo mês estava presente em seus achados. ${ }^{6}$

Uma questão presente no discurso dos próprios profissionais (saúde, educação e assistência social) que atuam no PBF se destaca nestas falas: a associação do benefício transferido com a compra exclusiva de alimentos. A frase, “não vou falar 'ah, é só pra comer”, e da entrevistada, ao dizer que gastou seu dinheiro com o tênis do filho, exemplificam a existência dessa associação.

As falas que apresentamos indicam que, em algum momento (seja na unidade de saúde, na escola, na vizinhança, em casa), essas mulheres foram confrontadas com a perspectiva de que o gasto do benefício do PBF fosse realizado exclusivamente com alimentação.

O histórico das políticas brasileiras de combate à fome pode ter relação com essa cobrança intrínseca ao discurso de alguns profissionais de saúde. Segundo Leão \& Castro, ${ }^{9}$ o Programa Bolsa Alimentação introduziu a vinculação entre o serviço de saúde e as políticas de transferência monetária. É possível que esta primeira experiência de transferência direta de renda, que teve origem na transformação de experiências anteriores de outras modalidades de transferências Programa Leite é Saúde (PLS) e Incentivo de Combate às Carências Nutricionais (ICCN) -, tenha influenciado diretamente a compreensão e atuação de profissionais de saúde. O desdobramento desta influencia é a ideia de que o dinheiro transferido às famílias deve ser gasto com alimentação. Entretanto, é preciso vislumbrar que a mudança nessas políticas teve como objetivo garantir mais autonomia às famílias na utilização dos recursos recebidos. Nesse sentido, segundo Suplicy: ${ }^{10}$ "Se o objetivo é erradicar a fome e a miséria, é preciso compreender que a pessoa pobre necessita mais do que matar a fome. Se está fazendo frio, precisa comprar um agasalho ou um cobertor. Se a telha ou porta de sua casa estão avariados, é preciso conserta-los. Se um filho ficou doente, é preciso comprar remédio com urgência. Se é o dia do aniversário de uma filha, é possível que a mãe queira lhe dar de presente um par de sapatos. Se a vizinhança está vendendo um tipo de alimento muito barato, é bom comprar, porque vai sobrar mais para outras coisas” [...]

Nessa passagem, Suplicy ${ }^{10}$ reforça ainda um discurso que está presente na literatura, que se refere à influência da transferência monetária direta na economia do país. ${ }^{11}$ A injeção de capital 
em pequenos municípios, por exemplo, pode gerar movimentação financeira e aquecimento dos mercados locais, o que é muito favorável para seu desenvolvimento.

Diversos estudos $2,11,12$ demonstraram que induzir a utilização do benefício do PBF na compra de alimentos é, no mínimo, desnecessário, pois já é percebido que este tem sido majoritariamente o destino do dinheiro recebido por essas famílias. Um desses estudos aponta que o PBF teve impacto sobre a cesta alimentar das famílias, garantindo aumento das parcelas de consumo com alimentação, educação e roupas infantis. ${ }^{12}$

A pesquisa do $\mathrm{IBASE}^{2}$ apresenta que o dinheiro do PBF é gasto principalmente com alimentação (87\%), material escolar (46\%) e vestuário (37\%). Ainda segundo o mesmo trabalho, pode-se perceber que quanto maior o nível de pobreza, maior a proporção da renda gasta com alimentação. Burlandy ${ }^{11}$ também destaca que estudos sobre os programas de TR de países como Nicarágua, Colômbia, México e países africanos demonstraram aumento médio nos gastos com alimentação.

É incontestável o impacto relacionado ao maior acesso a alimentação que o PBF traz, o que tem relação direta com o estado nutricional das famílias assistidas. Apesar dos baixos valores dos benefícios transferidos, especialmente se considerarmos o custo da cesta básica e a inflação acumulada no país, podemos ver sua importância, sobretudo nas famílias em extrema pobreza, como relatado a seguir:

[...] "tem diminuído também a fome, porque tem gente que fala: "ah cem reais não é nada"... é... porque quanto você olha no seu armário e não vê [voz embargada]... chegou cem reais, é tudo de compra. Eu falo: nisso o Bolsa Família ajudou muito." (2P).

Outra ideia muito comum difundida entre os beneficiários, e que muito possivelmente se relaciona com a herança das políticas sociais anteriores é que, para muitas famílias, o benefício variável (condicionado a existência de crianças, adolescentes e ou gestantes) é exclusivo para aquele indivíduo, como podemos observar no discurso a seguir:

"Me ajudou bastante. Mais pra minha filha, porque lá em casa eu tiro mais o Bolsa Família pra escola, pra comprar material. Até a fruta dela, tudo que é dela. Eu uso com ela. "(5P)

Santos ${ }^{13}$ também descreve que o significado local para o benefício federal transferido para o núcleo familiar foi que o mesmo era dirigido para a criança. A compreensão da autora é que, no contexto estudado, "a família inscrita no 'Bolsa Família' tende a ser lida localmente pelos moradores, como os filhos” (p.15). No entanto, é importante destacar que uma das características dessa política é a realização da transferência direcionada ao núcleo familiar e não apenas ou exclusivamente a um dos seus integrantes. Isso difere substancialmente dos repasses financeiros direcionados a integrantes da família que necessitam de assistência especial por qualquer motivo. 
Retomando as diversas dimensões da "ajuda”, encontramos relatos que questionam a suficiência dessa ajuda diante da situação de vida dessas famílias. As falas demonstram a noção de que, além de ser incapaz de suprir financeiramente as necessidades básicas da família, esta ajuda não se estende a outros elementos que as entrevistadas consideram fundamentais para a mudança em suas vidas. Questionados sobre as mudanças em sua vida desde a entrada no PBF, responderam:

"Na minha situação não mudou nada, né? Eu terminei os estudos, né, tive condições de terminar. Mas é um segundo grau que não te dá opção de coisa nenhuma, porque não é um segundo grau profissionalizante. A minha filh a também terminou e tá lá parada. Primeiro emprego é aquilo, né? Não tem experiência, não trabalha. E o primeiro emprego deles é enfiar você numa obra de PAC ${ }^{* * * *}$. É 0 primeiro emprego deles, você pode ver lá no cartaz. Obra de PAC... é... sei lá, eu sei que não ajudou muita coisa. Tem que correr, né? E eu queria poder ajudar ela a terminar uma faculdade, né? Alguma coisa assim... Mas, com uma ajuda assim, fica difícil..." (2U).

"Olha, eu acho que... numa parte ajuda, mas não é o suficiente. O suficiente, eu acho que é o marido ter seu emprego, entendeu? Porque aquilo ali é uma ajuda, não vou dizer que... realmente me ajuda bastante, mas eu acho que não supre. [...] A gente, pai de família, quer um trabalho, um emprego. Porque você com seu emprego, poxa... é outra coisa. Com certeza, aquilo ali não... não vou dizer que não ajuda, como ajuda, né?"(6E)

Como podemos ver, apesar de ter capacidade limitada de transformação da vida dessas famílias, essa ajuda não é algo que pode ser descartado na circunstancia de vida em que se encontram. O trabalho surge, então, como questão problema, já que fica explícito, inclusive pelos critérios de elegibilidade do programa, que esse benefício só existe em função da inexistência do trabalho. Daí essa insuficiência, relacionada com a falta, a desapropriação do trabalho como parte da vida da família, como meio de sobrevivência e, segundo Engels, ${ }^{14}$ como categoria fundante da vida humana.

É dessa realidade que trata Castel, ${ }^{15}$ ao descrever a situação da classe trabalhadora francesa que, desfiliada da chamada sociedade salarial, vê suas segurança e inscrição social danificadas. No caso brasileiro, os chamados programas complementares, que incluem a realização de ações de geração de emprego e renda, não garantem a inserção de todo beneficiário no mercado de trabalho.

No campo dos programas complementares, a geração de emprego e renda ainda se coloca muito aquém do desejado para possibilitar a entrada do beneficiário no mercado formal de trabalho e saída do programa. Pesquisa realizada no município de Montes Claros, Estado de Minas Gerais, ${ }^{5}$ demonstrou a percepção dos beneficiários sobre a incipiência dessas ações. Quando questionados sobre o desenvolvimento da condição de emprego, a maioria dos beneficiários respondeu não ter melhorado depois do ingresso no PBF. *** O Programa de Aceleração do Crescimento (PAC), criado em 2007, visou à retomada do planejamento e
execução de grandes obras de infraestrutura social, urbana, logística e energética do país. 
Santos \& Magalhães ${ }^{16}$ confirmam essa percepção, por meio das falas dos gestores do programa no município do Rio de Janeiro. As autoras revelam que os gestores assumem a baixa oferta de programas complementares, e que os existentes não dialogam com as demandas dos beneficiários, já que sua implementação se deu de forma vertical. Ainda segundo as autoras: "Ao desconsiderar o contexto local e não reconhecer as demandas e especificidades das famílias beneficiárias, dificilmente os programas complementares conseguirão alcançar seus objetivos de emancipação sustentada e de autonomização das famílias beneficiárias."

\section{Transferência de renda: direito ou ajuda?}

A centralidade da transferência de renda nas políticas sociais desenvolvidas para combater a fome e a pobreza nos permite questionar o papel que a TR assume nestas políticas. É importante diferenciar a transferência de renda da distribuição de renda. Registramos certa aproximação entre esses dois conceitos no marco legal de algumas políticas, sendo a transferência de renda entendida como medida de transição para uma redistribuição de renda em países com altos índices de desigualdade social.

No entanto, a própria implementação das políticas de transferência de renda, sua utilização em campanhas políticas e programas de governo e sua representação para beneficiário de programas de TR demonstram grande limitação no que se refere à possibilidade real de conduzir a TR a uma redistribuição de renda e constituição de direitos.

Das principais políticas de renda mínima da América Latina, Fonseca \& Viana ${ }^{17}$ destacam pelo menos três similaridades entre elas: o foco em famílias, pobres ou extremamente pobres, com crianças e adolescentes (com algumas exceções como o programa do Uruguai, que é mais amplo); o princípio das contrapartidas ou condicionalidades; e o não-pertencimento ao campo dos direitos.

De acordo com Salmón, ${ }^{18}$ o Programa das Nações Unidas para o Desenvolvimento (PNUD) descreve a pobreza como "uma situação que impede o indivíduo ou sua família de satisfazer uma ou mais necessidades básicas e participar plenamente da vida social” (p.154). O fenômeno tem bases fundamentalmente econômicas, apesar de estar permeado por dimensões sociais, políticas e culturais.

Costa ${ }^{19}$ problematiza que uma das dificuldades em se criminalizar/punir as chamadas "violações dos direitos humanos" está no fato de estes não estarem todos consolidados em forma de marco legal nas nações. Segundo ela, afirmações como a "pobreza é, por si só, uma violação de vários direitos humanos fundamentais" (p. 89) traduzem a posição política de que a pobreza não garante condições de desenvolvimento pleno do ser humano.

Essa abordagem ${ }^{19}$ traz elementos para se discutir a pobreza como violação de direitos, o que ainda é não está descrito e implementado de forma clara em políticas de combate à pobreza e sistemas legais. Segundo a autora, a pobreza é consequência de uma série de violações de direitos 
e precisa assim ser analisada e combatida. Na medida em que enxergamos a pobreza de modo mais geral como uma violação de direito, não especificamos suas múltiplas causas e podemos recair em um conceito moral que se distancia de uma postura política para analisar suas origens.

Se entendemos que a pobreza se constitui a partir de várias violações de direitos; tais violações não possuem atualmente critérios de exigibilidade jurídica; e que as políticas de transferência condicionada de renda historicamente não se debruçaram sobre estas violações, podemos concluir que a transferência de renda por si só não poderia se constituir como direito. De alguma forma, a TR, ao associar direitos sociais à transferência do benefício financeiro, tem-se debruçado sobre as violações de direitos causadas pela pobreza, e não sobre as violações de direito que originam a situação de pobreza. Vemos no exemplo brasileiro que, apesar de amenizar mazelas emergenciais da extrema pobreza e promover o acesso a direitos sociais universais como saúde e educação, o PBF não vem conseguindo atuar de forma consistente na redução da desigualdade social e na inserção dos beneficiários no mercado de trabalho, ações de cunho mais estrutural em direção a uma porta de saída do programa e também da pobreza.

$\operatorname{Costa}^{19}$ ainda reforça que, ao trabalharmos a pobreza em sua dimensão de negação de direitos humanos, não podemos nos remeter apenas aos direitos econômicos e sociais, mas aos direitos civis e políticos que são igualmente negados ao ser humano em situação de pobreza. Vemos, portanto, que a pobreza não só viola os direitos humanos, como o faz de forma completa, abarcando praticamente todas as dimensões da vida e da constituição humana.

Assim sendo, reforçamos aqui a necessidade de refletir sobre o papel das políticas de transferência de renda, que, não por acaso, figuram apenas como uma “ajuda” para seus beneficiários, não sendo citadas nunca como um direito.

\section{Considerações finais}

O Programa Bolsa Família foi um marco histórico importante, ao introduzir a política de transferência direta de renda com condicionalidades no marco das políticas sociais brasileiras. Poucas mudanças de fundo foram observadas ao longo da implementação e expansão do PBF. No entanto, a grande abrangência e o impacto na renda e no estado nutricional das famílias assistidas pelo programa precisam ser destacados.

Ao privilegiar o olhar do beneficiário sobre a transferência direta de renda, entendemos que essa medida emergencial não pode ser descartada na condição em que se encontram. No entanto, a representação do benefício para esses sujeitos culminou com a construção da categoria ajuda.

Os principais pontos que destacamos sobre esta categorização são: a constatação de insuficiência do benefício diante das necessidades da família; a desconsideração deste benefício enquanto 
direito, ou seja, o entendimento de que o mesmo é algum tipo de concessão; e o sentimento de desfiliação do mercado de trabalho, que gera desvalorização pessoal e sensação de inércia social, não solucionados pelo programa.

Estas conclusões demonstram a fragilidade do PBF no que se refere à construção de cidadania, tanto na perspectiva do conhecimento/empoderamento dos direitos do cidadão, quanto na criação de portas de saída do programa e inserção no mercado de trabalho.

Ademais, entendendo que uma política pública é construída e se desenvolve a partir das representações de quem a implementa, indicamos ser necessário entender e estudar mais as compreensões de profissionais de saúde, educação e assistência social envolvidos com o PBF.

As mudanças e adaptações nesses programas também precisam ser consideradas, ao se investigar o projeto de política social adotado no Brasil. Recentemente incorporado ao Bolsa Família, o Brasil Carinhoso é uma medida que, além de trazer novos elementos (relacionados a saúde e educação), impacta diretamente no benefício a ser transferido as famílias do programa, focalizando e agregando mais valor a famílias com crianças. O impacto dessas medidas e sua representação para os beneficiários precisarão ser investigados ao longo de sua implementação.

Contudo, é possível identificar que essas medidas não trazem novos marcos para o programa e pouco afetam as dificuldades e impasses apontados pelas falas dos beneficiários aqui apresentadas. As questões relacionadas ao empoderamento do sujeito através de informação e comunicação com instâncias governamentais e as chamadas políticas complementares que tratam da dimensão do trabalho e geração de renda não são afetadas pelas novas medidas.

Por fim, apontamos a necessidade de incorporar, ao debate sobre as políticas sociais brasileiras, discussões sobre violação dos direitos humanos na pobreza e a criação de mecanismos de criminalização destas violações, se o objetivo é avançar na diminuição da desigualdade social e ultrapassar os limites dos programas de transferência de renda.

\section{Referências}

1. IPEA. Objetivos de desenvolvimento do milênio: Relatório nacional de acompanhamento. [S.1.: s.n.]; 2010.

2. Instituto Brasileiro de Análises Sociais e Econômicas. Repercussões do Programa Bolsa Família na Segurança Alimentar e Nutricional das Famílias Beneficiadas: Documento Síntese. [S.l.: s.n.]; 2008.

3. Brasil. Secretaria Nacional de Renda de Cidadania. Apostila compilada pela Equipe de Capacitação/ MDS/Senarc. Brasília: [s.n.]; 2009.

4. Minayo MCS. O desafio do conhecimento pesquisa qualitativa em saúde. 10a ed. São Paulo: HUCITEC; 2008. 
5. Barbosa JFP et al. O Programa Bolsa Família, como medida de combate à pobreza: uma análise de alguns de seus impactos no município de Montes Claros-MG. [Anais do] XIII Seminário sobre a Economia Mineira; 2008; Diamantina, MG: [s.n.]; 2008.

6. Magalhães R et al . A implementação do programa Bolsa Família: as experiências de São Francisco de Itabapoana e Duque de Caxias. Ciênc. saúde colet. 2007 jan.;12(6).

7. Hevia FJ. Relaciones lejanas. Cantidad y calidad de información que poseen lós beneficiarios sobre el programa Bolsa Familia. [S.l.: s.n.]; 2008 [Acesso em : 2009 out.]. Disponível em: <http://www. ipc-undp.org/mds.do>.

8. Silva RR. Programa Bolsa Família: necessidades de metodologias de avaliação para identificar a sua potencialidade na construção da cidadania. Revista Ágora: Políticas Públicas e Serviço Social. 2006 jul.;2(4).

9. Leão MM, Castro IRRC. Políticas públicas de alimentação e nutrição. In: Kac G, Sichieri R, Gigante DP. Epidemiologia nutricional. Rio de Janeiro: Fiocruz: Atheneu; 2007.

10. Suplicy EM. O direito de participar da riqueza da nação: do Programa Bolsa Família à Renda Básica de Cidadania. Ciênc saúde colet. 2007;12(6).

11. Burlandy L. Transferência condicionada de renda e segurança alimentar e nutricional. Ciênc saúde colet. 2007;12(6).

12. Soares FV, Ribas RP, Osório RG. Avaliando o impacto do Programa Bolsa Família: uma comparação com programas de transferência condicionada de renda de outros países. Brasília: Centro Internacional da Pobreza; 2007. (IPC evaluation note, 1). Disponível em: <http://www.ipc-undp.org/pub/port/ IPCEvaluationNote1.pdf $>$

13. Santos JC. Direito ou privilégio: o Programa Bolsa Família e o significado local. [S.1.: s.n.]; 2008 [Acesso em : 2009 out.]. Disponível em: <http://www.ipcundp.org/mds.do>

14. Engels F. O papel do trabalho na transformação do macaco em homem. 4a ed. Global: São Paulo; 1990.

15. Castel R. As metamorfoses da questão social: uma crônica do salário. Petrópolis, RJ: Vozes; 2008.

16. Santos CRB, Magalhães R. Pobreza e Política Social: a implementação de programas complementares do Programa Bolsa Família. Ciênc. saúde colet. 2012 maio;17(5):1215-24.

17. Fonseca AMM, Viana ALA. Direito à saúde, atenção básica e transferências condicionadas de renda na América Latina. Ciênc. saúde colet. 2007 dez.;12(6).

18. Salmon GE. O longo caminho da luta contra a pobreza e seu alentador encontro com os direitos humanos. Sur, Rev int. direitos human. 2007;4(7).

19. Costa FD. Pobreza e direitos humanos: da mera retórica às obrigações jurídicas: um estudo crítico sobre diferentes modelos conceituais. Sur, Rev int. direitos human. 2008;5(9):88-119.

Recebido: 30/10/2012

Aprovado: 25/11/2012 